\title{
Anticipating emerging genomics technologies: The role of patents and publication for research and policy strategies
}

\author{
RENS L.J. VANDEBERG \& WOUTER P.C. BOON ${ }^{1}$
}

\begin{abstract}
There is an increasing interest in scanning and assessing the science and technology landscape for emerging technologies - such as those based on genomics knowledge because innovations are beneficial to businesses and nations, and because of the Collingridge dilemma. The latter concerns the uncertainty and manageability of technology in its early development phases versus the more solidified later stages. In this context, the assessment of upcoming scientific and technological (sub)fields or "hot spots" is of interest. In this paper we focus on methods to identify hot spots in pharmacogenomics and nutrigenomics and how this method can contribute to policy strategies. Moreover, the bibliometric results contribute to our understanding of hot spots within these genomics subfields. We answer the following leading research question: What are the main research fields of emerging pharmacogenomics and nutrigenomics technologies and how do these impact policy strategies? First, this paper introduces a novel method for identifying hot spots in emerging technologies. Following this method, pharmacogenomics and nutrigenomics show an above-average growth in patent applications. Patent search also suggests that for pharmacogenomics, countries such as Italy and France, and subfields such as cancer genomics are highly visible. For nutrigenomics, the Netherlands and Austria are important countries, while the dairy subfield proves to be a hot spot. Second, we discuss implications for policy strategies. We argue that it is difficult for policymakers to follow hot spots when they design their policy, because of the inherent tendency to "nurture" winners instead of "picking" fundamental new winners. Policymakers should be aware of this bias and research should address this issue by, for example, complementing the hot spot analysis with more interactive methods.
\end{abstract}

\section{Introduction}

The "new" has always drawn attention: it is exciting, challenging, expands possibilities and encompasses dangers. New technological developments include both promises and threats. These so-called emerging technologies are defined as technologies that are in an early stage of development, in which there are no - or hardly any - products commercially available yet, ${ }^{2}$ and there is no dominant design. ${ }^{3}$ This means that a lot of aspects, such as the network of stakeholders involved, public acceptance, demand, and the technology characteristics themselves, remain uncertain, abstract and "fluid". At the same time, these technologies attract a large share of attention because of the proposed promises - a personalised diet in nutrigenomics, for example, or tailor-made drug in pharmacogenomics. They are eye-catching and through projections involve great expectations, promises and the possible composition of hype (ie, excessive attention for the new technology). Examples of these kinds of technologies are stem cell therapy, gene therapy, and genomics. The latter includes a large range of subcategories, such as ecogenomics, industrial genomics, and

Genomics, Society and Policy, Vol.5, No.2 (2009) ISSN: 1746-5354

(C) ESRC Genomics Network. 
agricultural genomics. In this paper we will focus on two important and highly visible genomics areas: nutrigenomics and pharmacogenomics (see Box 1).

\section{Box 1: History and definition of nutrigenomics and pharmacogenomics}

The Human Genome Project resulted in the pub lication of a (near) co mplete map of the human genome in 2001. ${ }^{5}$ It also marked the begin ning of the functional geno mics era: researchers were beginning to identify "which genes do what, when and why". This new knowledge base provides insight into $t$ he interaction between the hu man body and, for example, medicines or food ingre dients. The clarification of gene-environm entinteractions is surrounded by high expectations and uncertainties about fut ure products, processes an d services. Within functional genom ics two major area s of interest a re visible: nutri genomics an d pharmacoge nomics. Nutrigenom ics is about "the study and application of gene-nutrient interactions". ${ }^{6}$ Nutrigenom ics is seen as a "grand challenge" that might result in a solution to the metabolic sy ndrome. "The metabolic syndrome is a common metabolic disorder that results from the increasing prevalence of obesity". According to the WHO, "Obesity is one of the greatest public health challenges of the 21 st century. [..] Obesity is already responsible for 2-8\% of health costs and 10-13\% of deaths in different parts of [Europe]". "The em erging techno logy of nutrigenomics can be seen as contributing to th e fight against obesity and the metabolic syndrome. ${ }^{10}$ The expectations of scientific de velopments in nutrigenomics have stimulated the formation of various consortia ${ }^{11}$ in wh ich stakeholders inter act and learn from each other. ${ }^{12}$ Pharmacogenomics is defined as "the study of the variability of the expression of individual genes relevant to disease susceptibility as well as drug response at cellular, tissue, individual or population level". ${ }^{13}$ Also for pharmacogeno mics, great expectations have been put on the agen da. It might lead to the stratification of the patient population and more tailor-made drugs. Am ongst others, it woul d benefit both patients, because of le ss adverse dr ug reactions and high efficacy , ${ }^{14}$ and com panies that can use pharmacogenomics knowledge to make their drug R\&D process more efficient. ${ }^{15}$

In recent years, science and technology studies have increasingly embraced these socalled emerging technologies as objects of study because they provide an enlarged view of the co-construction of society and technology. ${ }^{16}$ These processes are characterised by high levels of uncertainty, instability, undisciplined stakeholders, promises, and "newness". All these qualities have major repercussions for innovation managers, public policymakers and innovation researchers. Take for example the notion of "newness". From the innovation policy perspective it might be important to establish whether a technology is emergent as part of rhetoric efforts or because the technology is intrinsically novel in itself. ${ }^{17}$ With regard to this, the performative and constitutive role of expectations should be mentioned in the sense that the characteristics of technologies themselves are not the only determinants of whether and how these technologies are going to be used. Expectations and promises can be performative when they turn into requirements, and in this way result in a selffulfilling prophecy. ${ }^{18}$ Another important feature of expectations is that actors interpret technologies and its characteristics, such as the degree of novelty, differently. This is partially the result of actors' past and present experiences and knowledge asymmetries. $^{19}$

There are two major reasons to scan and assess the science and technology landscape for emerging technologies. First, businesses that are capable of creating novel products, processes or services seem to generate a competitive advantage. ${ }^{20}$ Commercialising or translating scientific findings into successful innovations could

Genomics, Society and Policy, Vol.5, No.2 (2009) ISSN: 1746-5354

(C) ESRC Genomics Network. 
form a relative advantage for these businesses and keep them at the high-margin forefront of their sector. Also society and countries as a whole can benefit from innovations, ${ }^{21}$ not only in order to solve societal or individual problems but also to increase national wealth levels. Therefore, creating policy strategies that stimulate the development of these opportunities is highly recommended and even necessary.

Second, the "fluidity" of emerging technologies creates the possibility of forming the future because all options are still open, but at the same time it is unknown what these options are. At a later stage of technological development, the options might have become clearer, but it is more difficult to steer towards particular options. This so called Collingridge dilemma ${ }^{22}$ is of special interest when looking at ethical, legal and social impacts (ELSI) of emerging technologies. At first these impacts are not clear and the technology is "fluid"; as soon as the impacts start to become visible it becomes almost impossible to influence the technological development because the technology is "solidified".

Several scholars underline the importance of predicting the future of the technology by performing technology future analyses, technology foresight, technology forecasting, technology assessment, etc. Reasons for this are R\&D-priority setting, exploiting intellectual property rights, benchmarking performances, and anticipating potential societal impacts. $^{23}$

Before being able to study the ELSI aspects surrounding an emerging technology or in order to create and apply policy strategies regarding emerging technologies, these technologies have to be visible first. The first signs of an emerging technology appear through scientific articles and patents in a new field. An often-applied way of identifying these subfields is the use of scientometric methods in the search of socalled hot spots. ${ }^{24}$ Hot spots are interesting new subfields that show a large degree of expectations. The scientometric identification process makes it possible for scientists to study new developments without reverting to the "usual suspects": often-mentioned examples that might have started to live a life of their own. At the same time, the hot spot identification creates a method for agenda- and priority-setting for policymakers. They have a need for early identification of hot spots and often use scientometric methods, which have been explored extensively by scientists. Here, we contribute to the field in two ways. First, by identifying hot spots in two genomics fields in order to illuminate these two technologies and illustrate how hot spot analysis in the context of emerging technologies could be conducted. Second, we illustrate that applying for policy or management purposes the results could be problematic, especially in the case of emerging technologies.

Starting from the methodological quandary of the Collingridge dilemma, emerging technologies are important phenomena for scientists, innovation managers and policymakers who are interested in the co-construction of technology and society. Therefore, in order to develop a better understanding of the methods for identifying hot spots in emerging technologies and how these can be used for policy strategies, we formulate the following leading research question for our paper: What are the main research fields of emerging pharmacogenomics and nutrigenomics technologies and how do these impact policy strategies?

Genomics, Society and Policy, Vol.5, No.2 (2009) ISSN: 1746-5354

(C) ESRC Genomics Network. 
Our paper consists of three closely related parts. First, we present a method for identifying hot spots in emerging technologies ${ }^{25}$ on the basis of which scientists, innovation managers, and policymakers can decide on which interesting genomics developments to focus. Second, we present the empirical findings that shed light on the pharmacogenomics and nutrigenomics fields. Third, based on the identification and characterisation of emerging genomics technologies we discuss implications for policy strategies. In doing this, we combine quantitative patent activity methods with qualitative insights into patents' influence on science, society and policy - something which Oldham and Cutter ${ }^{26}$ put on the agenda.

\section{Data and methods}

When mapping an emerging technology field, some authors use the term hot spot analysis. ${ }^{27}$ In general, a hot spot stands out in its surroundings: it is "hotter" and "brighter"; it concerns subfields that attract more attention within or across research communities than others, or countries that outperform other countries on the same subject. Such awareness can usually be measured by publication citation analysis. Unfortunately, citation analysis is not a suitable tool to capture awareness of emerging technologies, as the number of citations of these technologies is generally assumed to be very low because they are influenced by a patent's or publication's age. To measure the latent concept of awareness, we assume that indicators based on patents and publications serve as proxies. Patent data, especially, show the areas in which companies find it worthwhile to invest, and therefore patent data indicate what might become available on the market in the near future. Patent data are used because patents protect investments in R\&D activities that businesses find worthwhile to pursue (or to prevent other companies pursuing), and are therefore indicators of developments in a field.

The reason for using publication data is that scientists are always looking for new developments. They write down their scientific journeys in articles through which we can develop a better understanding of new knowledge fields and the increase in attention scientists pay to these fields. Therefore, articles are an indicator for scientific activity in a field.

The relative growth of publications and patents in a specific R\&D subfield compared to other subfields (or an R\&D field in a country compared to other countries) indicates hot spots. The advantages and disadvantages of using patent and publication data as indicators of innovation are well known and thoroughly discussed by several authors. ${ }^{28}$ Pros include: the availability of historical time-series; the detailed classification by technological subfield; and easy access. Disadvantages include: differences in propensity to patents across countries, sectors and even over time; a disregard for other types of knowledge that cannot be patented or are not patented because of strategic reasons; differences in patent procedures across countries; and the inability to diversify between patents that are economically valuable and the ones that are not. Therefore, publications and patents are merely used as indicators. For example, for the pharmaceutical industry the propensity to patent is notably high because this is one of the major ways to protect innovation. ${ }^{29}$ But even here the

Genomics, Society and Policy, Vol.5, No.2 (2009) ISSN: 1746-5354

(C) ESRC Genomics Network. 
relationship between patenting and product introduction has become subject of debate: the relationship between patenting and approval of new drugs decreased in strength. ${ }^{30}$

Following the logic of patents and publications as proxies for awareness in emerging technologies, we focussed on the question of whether nutrigenomics and pharmacogenomics were hot spots themselves and if there are countries that are important contributors to these fields. Statistics of absolute and relative growth of the number of (pharmaco- and nutri-)genomics patents and publications were extracted from databases based on the classification schematics discussed below. The data were then analysed per country to see if there are differences that can influence, or are influenced by, country-specific circumstances or policy strategies. Regarding this, it is important to note that the comparison of countries based on growth rates or absolute amounts of R\&D output does not unpack country- and technology-specific differences in companies' inclination to produce R\&D output. To include this factor, the revealed technological advantage (RTA) indicator is used. ${ }^{31}$ This is an index that shows the extent to which a country $I$ is specialised in a technology or sector $J$. This is then calculated by the national share of patenting in that particular sector divided by the national share of patenting in all sectors. Logically, a value above unity means a relative specialisation of a country in that technological area, while a value below 1 reflects a relative under-specialisation.

$$
R T A_{I J}=\left(\frac{P_{I J}}{\sum_{J} P_{I J}}\right) /\left(\frac{\sum_{I} P_{I J}}{\sum_{I J} P_{I J}}\right)
$$

A standardised or normalised version of this formula is the NRTA $=(\mathrm{RTA}-1)$ / $(\mathrm{RTA}+1)$, which keeps the values between -1 and +1 . In the following section, we focus in detail on the method used for the patent analyses (in which the NRTA was used). We then take a closer look at the methods for publication analyses.

\section{Patent analysis}

The major challenge regarding statistical analysis of patent data lies in the proper definition of fields in order to retrieve statistically-representative samples. ${ }^{32}$ When defining technology fields, roughly three different strategies can be deployed: 1) classification based on the international patent classification (IPC) classes; 2) classification based on keywords; or 3) a combination of these two strategies. The IPC is an internationally agreed, highly hierarchical structure of sections, classes, subclasses, groups and subgroups in which patents are subdivided. A disadvantage of using IPC classes is its inertia: new, emerging technologies, such as gene therapy, are difficult to file under a class, because the class structure is only revised every seven years. ${ }^{33}$

Still, the IPC classes served as a starting point for determining the genomics fields. Even though a specific genomics classification has not been introduced, a proper and often-applied search strategy ${ }^{34}$ is to define fields by the cross-section of two different

Genomics, Society and Policy, Vol.5, No.2 (2009) ISSN: 1746-5354

(C) ESRC Genomics Network. 
pools of IPC classes. ${ }^{35}$ This connects well with the notion of the two genomics fields being multidisciplinary. For example, the nutrigenomics field combines nutrition with genomics. This cross-section is shown in Figure 1 (as NGx). Pharmacogenomics (PGx) is depicted as an intersection of pharmacology and genomics.

For the selection of IPC classes an iterative process was used: i) drawing upon experience of previous patent research in the field of biotechnology ${ }^{36}$; ii) scanning the International Patent Classifications books; and iii) interviewing experts to discuss keywords that are used in the genomics context and subsequently checking in the Espacenet ${ }^{37}$ database whether all relevant IPC classes were included and whether those included were relevant. An overview of the IPC classes that were used is shown in Annex A.

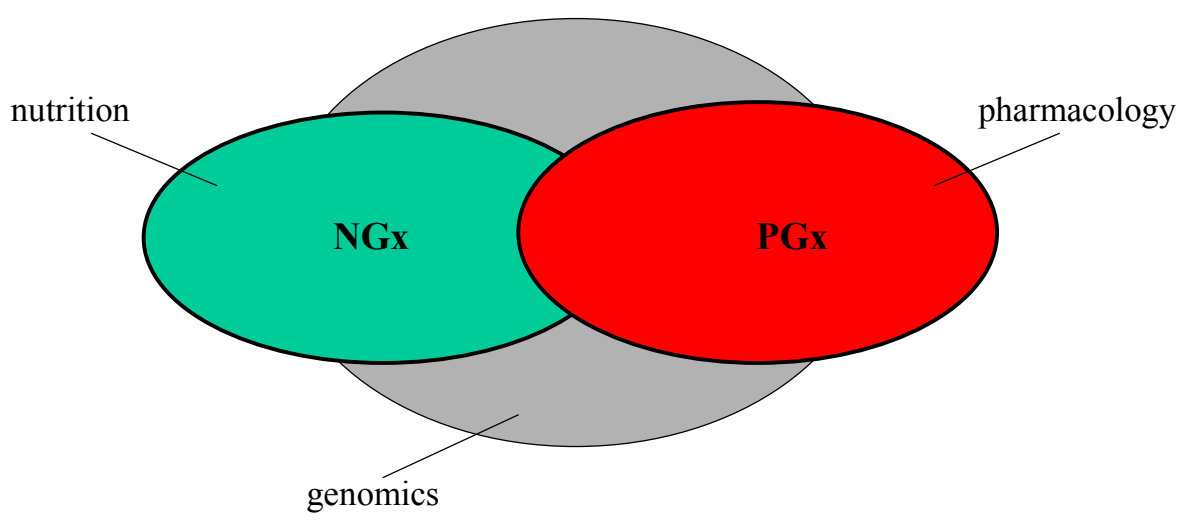

Figure 1: cross-sections of genomics, pharmacology and nutrition yielded the constructed fields of pharmacogenomics ( $P G x)$ and nutrigenomics $(N G x)$.

The patent search was conducted in the Questel database that incorporates patents from both the European Patent Office (EPAT; so-called EP applications) and the World Patents Index (WPI/L; so-called WO applications). The process from patent application to granted patent can take years. Using patent applications has the advantage that the newest entries are taken into account, which is of special interest when studying emerging technologies. In the end, some of these patent applications might not be granted. However, since we are not interested in specific de facto granted patents but in relative differences between technologies, this does not present a problem. The search is limited to European countries, the United States and Japan, and to the time-span of 1990 to 2002 . When the patent analyses were performed in spring 2005, the database did not include entries later than 2002. Relevant patent documents were collected based on primary and secondary IPC classification. 
The search resulted in three different overviews: 1) the number of genomics, pharmacogenomics and nutrigenomics patents over time as compared to the trend of all patents; 2) technological advantage indicators for pharmacogenomics and nutrigenomics for different countries; and 3) subfields within pharmacology and nutrition that prove to be pharmacogenomics and nutrigenomics hot spots. For the latter exercise, pharmacogenomics and nutrigenomics were divided into subfields. This was done by using IPC classes. In the case of nutrition, an exhaustive division based on different related IPC food classes was employed: dairy products (A01J, A23C), fats (A23D), plant products $(\mathrm{A} 01 \mathrm{G}, \mathrm{A} 01 \mathrm{H})$, coffee and tea products (A23F). The choice for pharmacogenomics subfields was grounded on disease areas that are present in IPC classes A61K ("medicinal preparations") and A61P ("therapeutic activity of chemical compounds or medicinal preparations"), such as drugs for disorders of the digestive system, metabolism, the endocrine system. In the pharmaceutical industry such a subdivision following disease areas is common. Moreover, the C12Q001-68 class is about testing, which plays an important role in the context of pharmacogenomics, ${ }^{38}$ and was also included.

\section{Publication search}

While using patents as an innovation indicator, publications are used as an indicator for scientific interest and activity. Two publication and conference paper abstract databases were consulted: Science Citation Index (via ISI Web of Science) and PubMed. ${ }^{39}$ The latter focuses mainly on medical publications, which especially proved to be of value when searching the pharmacogenomics field. Generally, both databases were suitable for the analysis of medical topics as the SCI covers a large number of journals from the field of medical research.

The search strategy focused mainly on using keywords, because an analogy of IPC classes did not exist in the two databases. The importance of the two genomics fields was investigated by determining the relative growth of publications in these areas. The first strategy used to construct this pool of pharmacogenomics and nutrigenomics publications was by using these terms literally as search words. The advantage was that the included data had a high probability of really belonging to that field. The second strategy was using a group of keywords that together described or "constructed" the pharmacogenomics and nutrigenomics fields. These keywords were collected by scanning relevant literature, and the relevance of these keywords was verified through interviews with experts in the field. The strategies are summarised in Annex B, which also contains the resultant numbers of publications. Moreover, an attempt was made to combine the results of the two strategies.

With regard to the validity of the search results, it was important to determine whether the publications that were found belonged to the fields of pharmacogenomics or nutrigenomics, or to both. It was assumed that the publications obtained by the "keyword" search strategy (ie, "pharmacogenomic(s)", "pharmacogenetic(s)"; "nutrigenomic(s)", "nutrigenetic(s)") comprise no false positive (ie, had a recall of $100 \%)$. On the other hand, the chance that publications were "missed" or not included while they should have, was expected to be high. In other words, the level of precision was rather low. This is because articles about pharmacogenomics or nutrigenomics do

Genomics, Society and Policy, Vol.5, No.2 (2009) ISSN: 1746-5354

(C) ESRC Genomics Network. 
not have to feature these terms in their titles or abstracts. For the combined strategy, the number of false positives was estimated by taking a sample of 100 publications. The titles, keywords, and abstracts of these publications were scrutinised. For pharmacogenomics, 68 out of 100 publications were true positives. Extrapolating this to the total population (with $\mathrm{p}=0.1$ ), between 64 to $72 \%$ of the publications in the population concerned pharmacogenomics. For nutrigenomics the recall was 33\%. These resulting recall percentages were not impressive and might easily lead to wrong conclusions. Therefore, we chose to work with the results from strategy 1, a search population with a high recall.

We also crossed the set of resulting publications with keywords based on expert interviews in order to obtain disease- (pharmacogenomics) or nutrition-specific subfields. This gave us insights into hot spots within the different genomics fields. The results of the patent and publication analysis, which identify pharmacogenomics and nutrigenomics hot spots, are presented in the next section.

\section{Results}

First we present the results of the patent search, followed by those of the publication analysis.

\section{Patent results}

UUDevelopments of the pharmacogenomics and nutrigenomics fields To get an overview of the development in genomics, the numbers of all patents, genomics patents, and pharmacogenomics and nutrigenomics patents per year were plotted as index figures in Figure 2 below. This shows an upward trend, which signifies pharmacogenomics and nutrigenomics innovations as fields that are steadily gaining momentum. ${ }^{40}$ Based on the pharmacogenomics and nutrigenomics (EP and WO) patents, and the total amount of genomics patents for each individual country, the NRTA was calculated, which represents the relative importance of nutrigenomics and pharmacogenomics patents compared to all genomics patents for each country (Figure 3).

Figures 4 and 5 illustrate the results for the subfields within pharmacogenomics and nutrigenomics. 


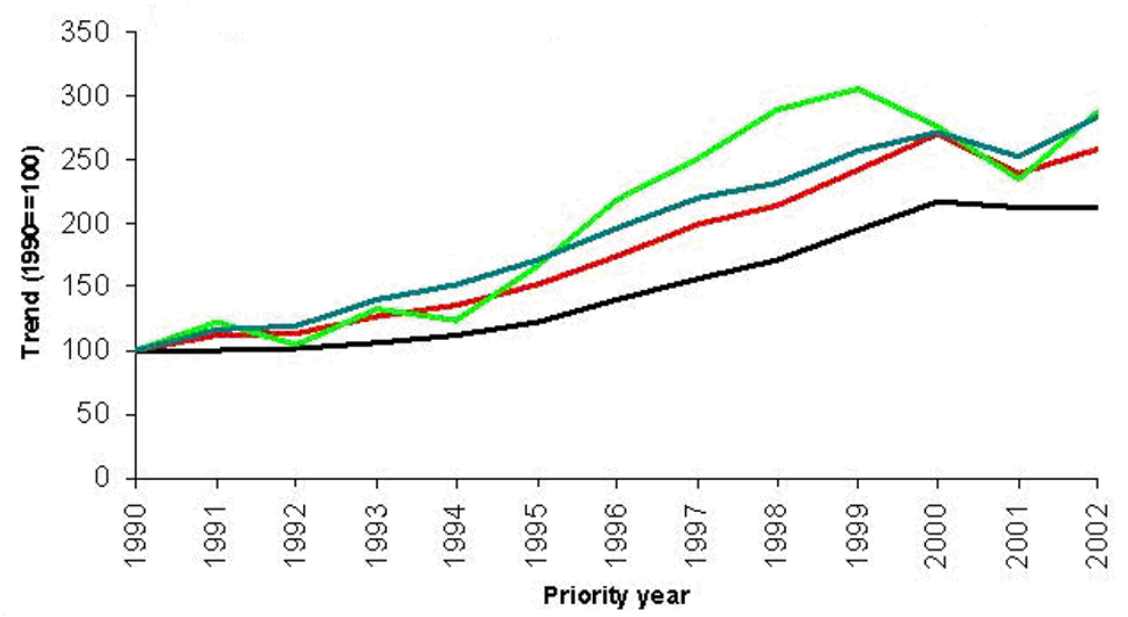

Reference — Genomics patents _-Nutrigenomics patents —Phamacogenomics patents

Figure 2: trend of applications of EP and WO patents in genomics, nutrigenomics and pharmacogenomics between 1990 and 2002.

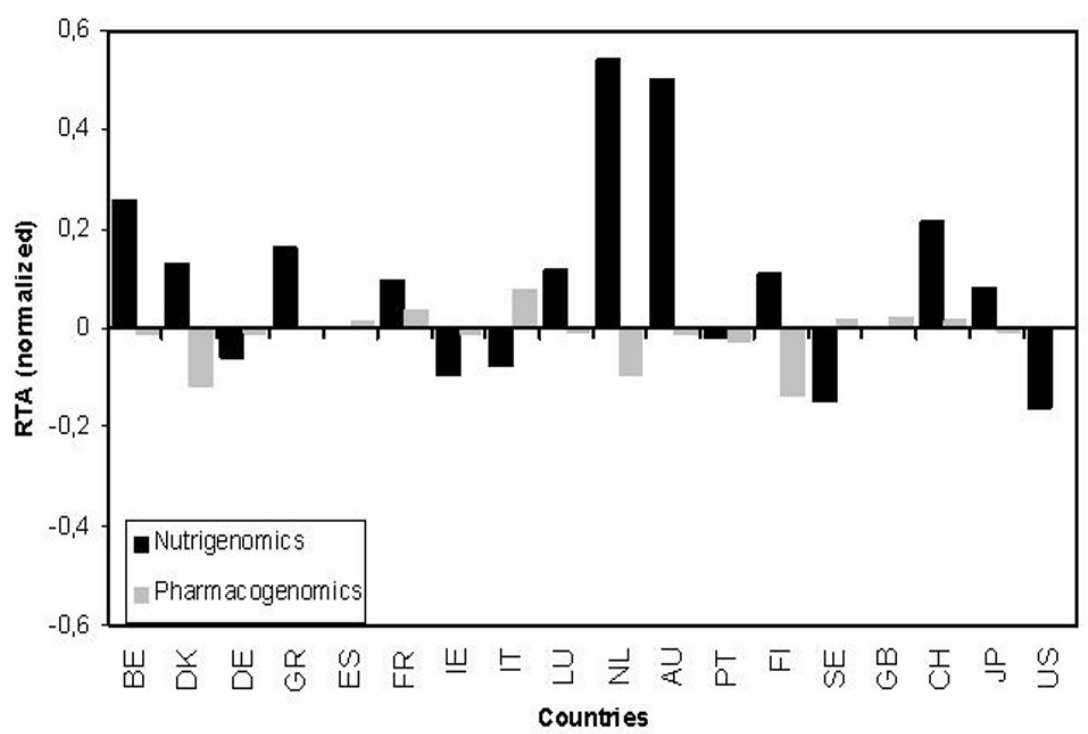

Figure 3: the NRTA of nutrigenomics and pharmacogenomics EP and WO patents compared to genomics EP and WO patents (period 1990-2002).

Genomics, Society and Policy, Vol.5, No.2 (2009) ISSN: 1746-5354

(C) ESRC Genomics Network. 


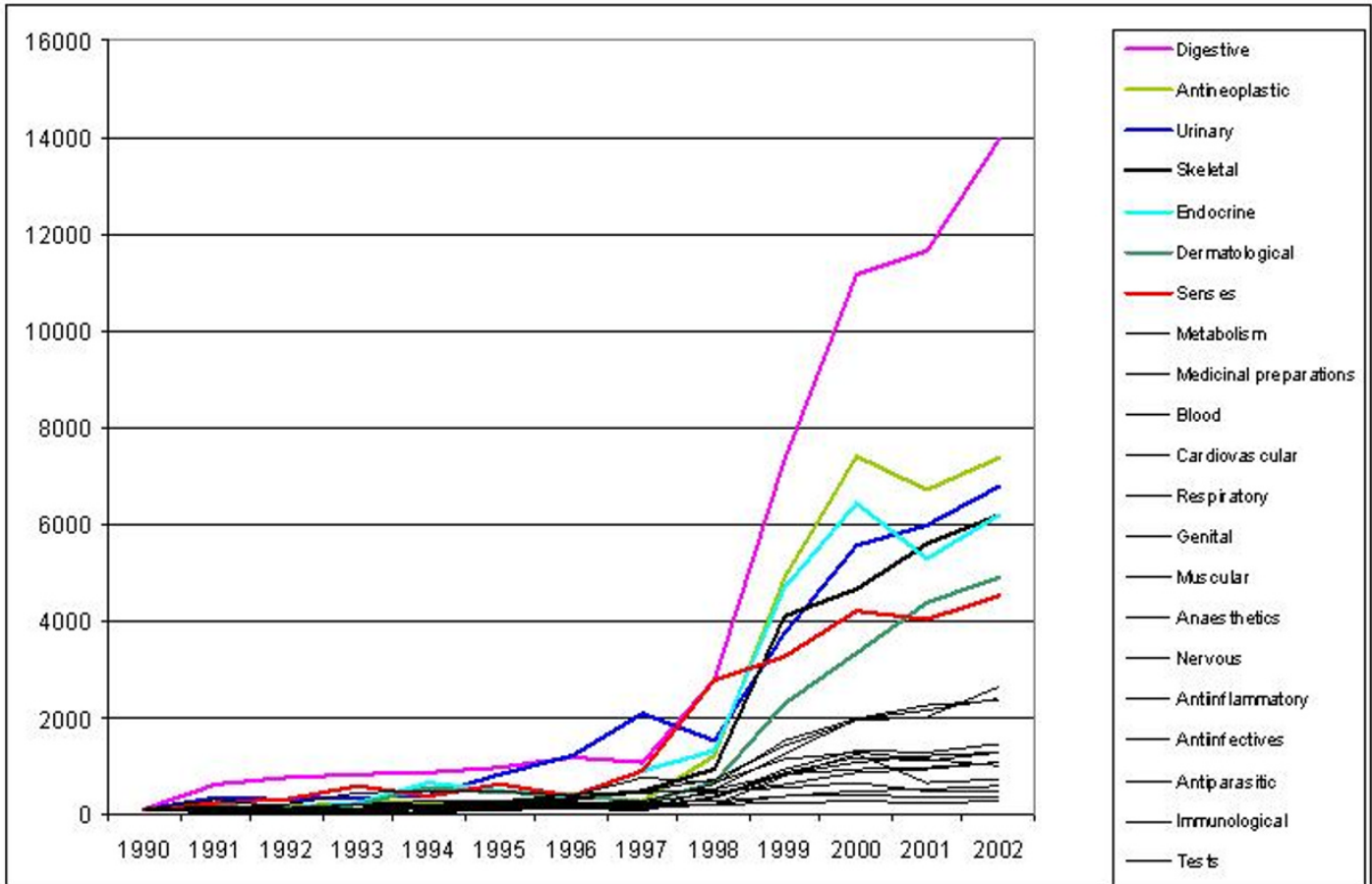

Figure 4: interesting subfields in pharmacogenomics EP \& WO patents based on patent analysis period 1990-2002 (only the fastest growing subfields are demarcated in colour).

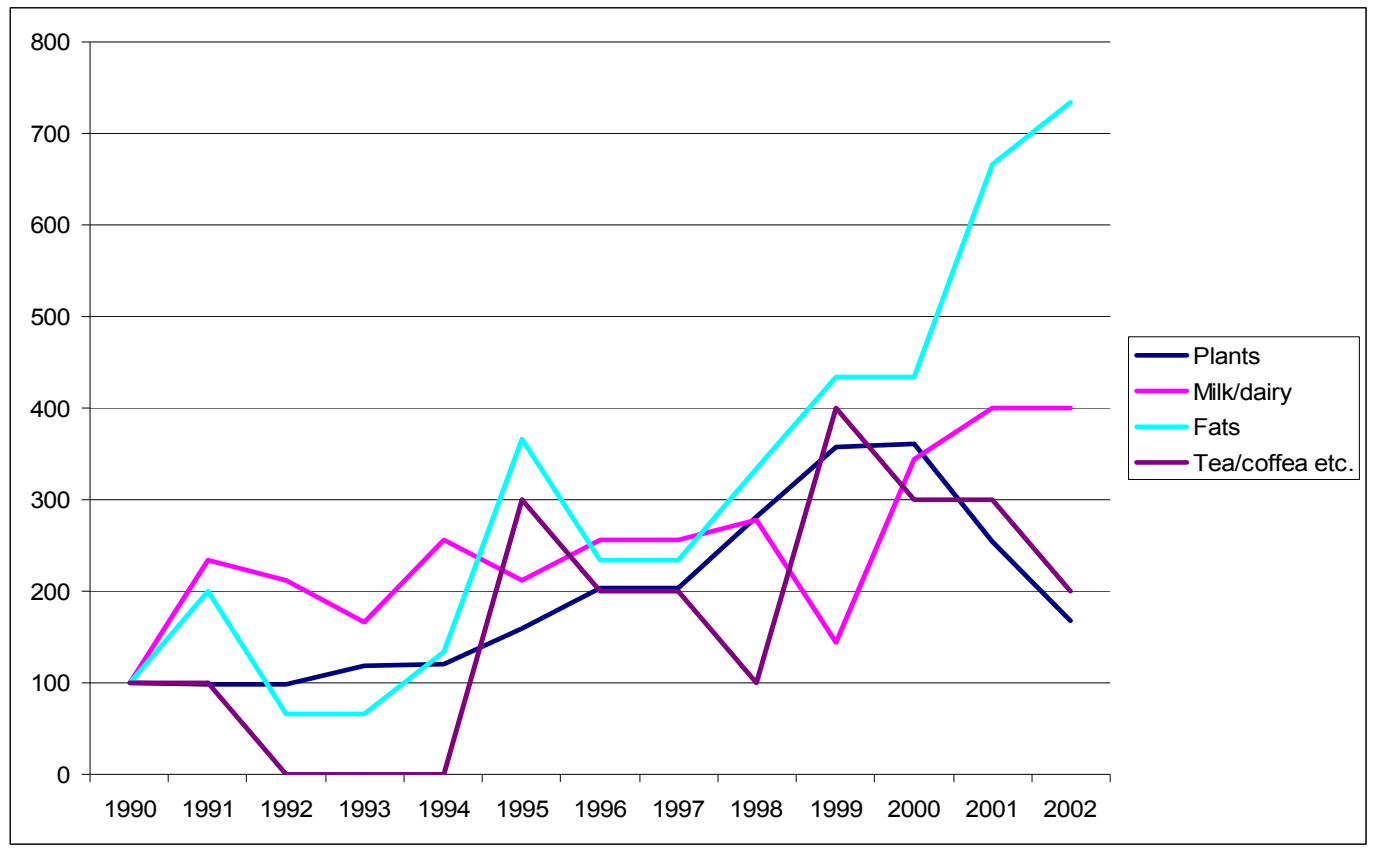

Figure 5: interesting subfields in nutrigenomics EP \& WO patents based on patent analysis period 1990-2002

Genomics, Society and Policy, Vol.5, No.2 (2009) ISSN: 1746-5354

(C) ESRC Genomics Network. 


\section{Publication results}

The first nutrigenomics articles were written in 2001, while the pharmacogenomics publications started in $1990 .^{41}$ Since then a clear exponential growth can be seen until 2004 (Figures 6 and 7). The drop after 2004 is due to the fact that the publication analyses were performed as part of a research in spring 2005 and therefore only the publications in the first quarter of 2005 were taken into account.

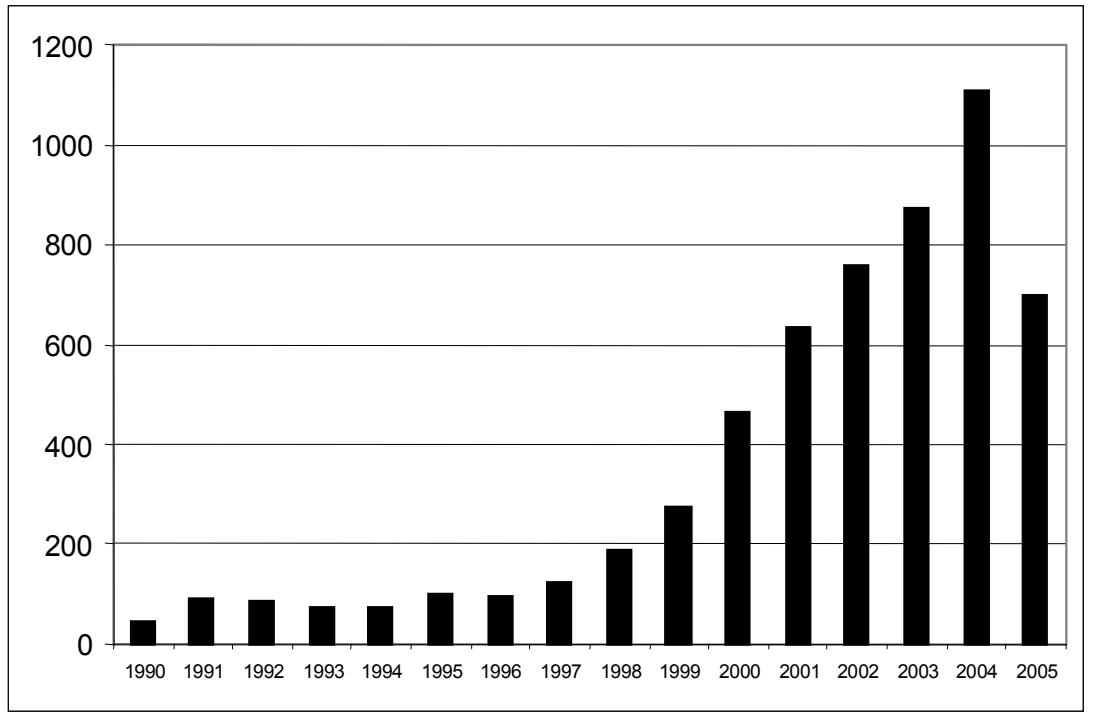

Figure 6: number of pharmacogenomics articles over the period 1990-2005

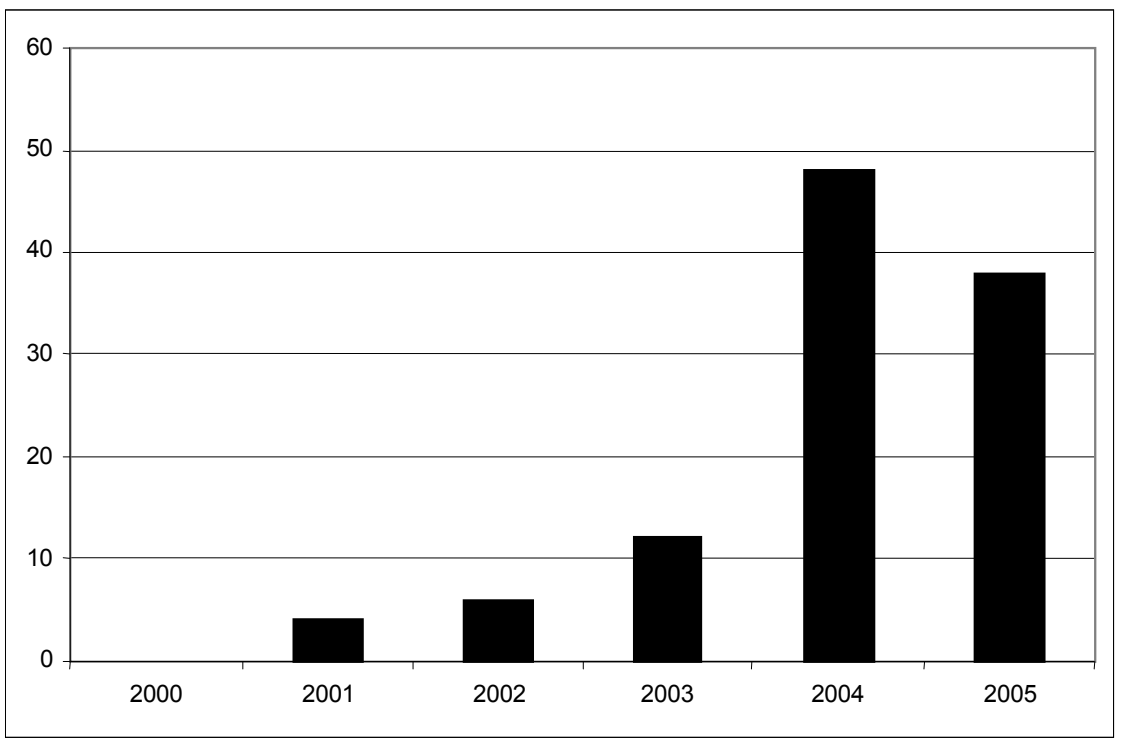

Figure 7: number of nutrigenomics articles over the period 2000-2005.

Also for the publication data an analysis was performed that shows the growth of publications per subfield of pharmacogenomics and nutrigenomics (Figures 8 and 9). These resulted in top rankings for drugs for the disorders in the metabolism, in the nervous system, in the urinary system, and for cancer (pharmacogenomics), and fats and coffee/tea products (nutrigenomics).

Genomics, Society and Policy, Vol.5, No.2 (2009) ISSN: 1746-5354

(C) ESRC Genomics Network. 


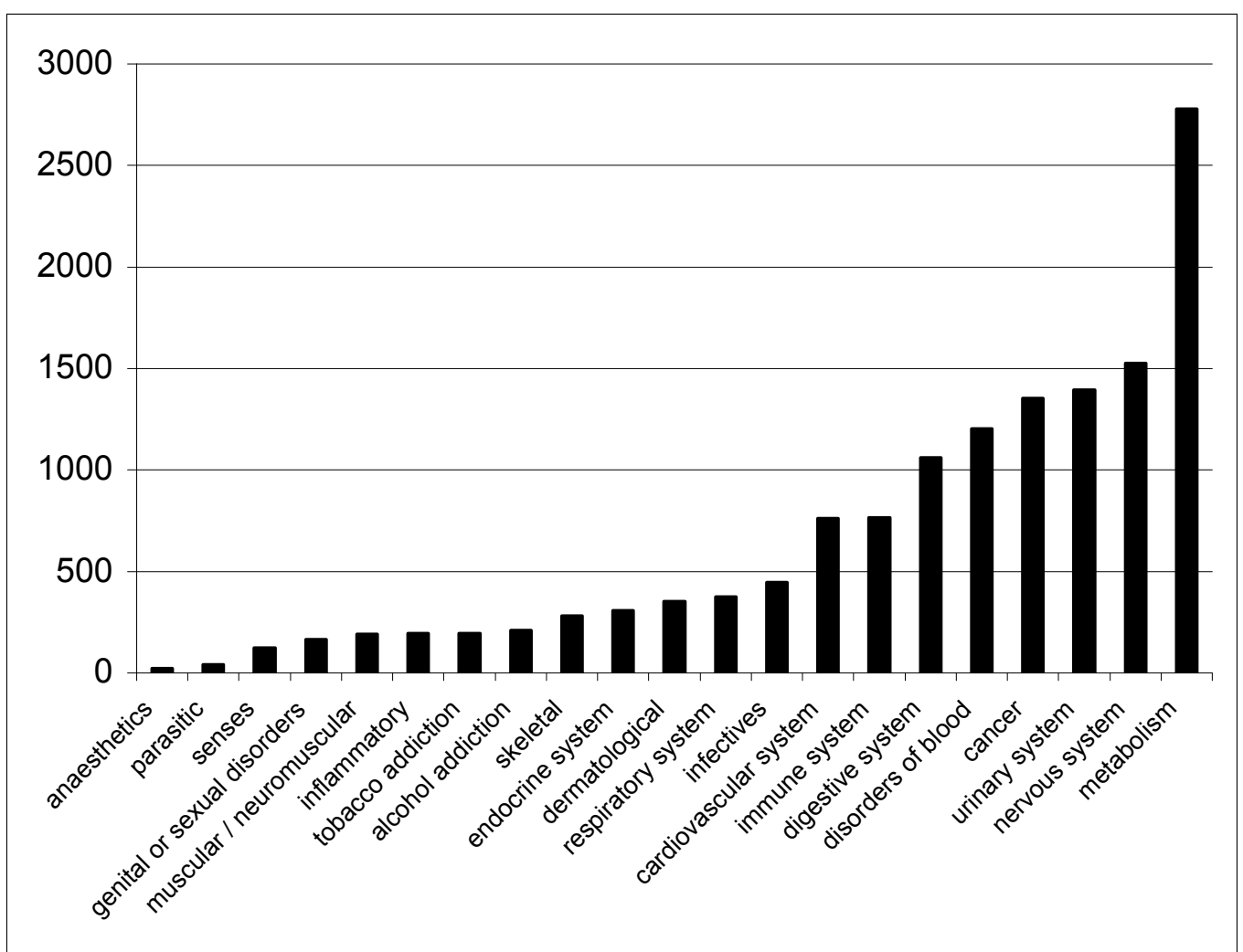

Figure 8: pharmacogenomics articles on disease areas $(N=13745)$.

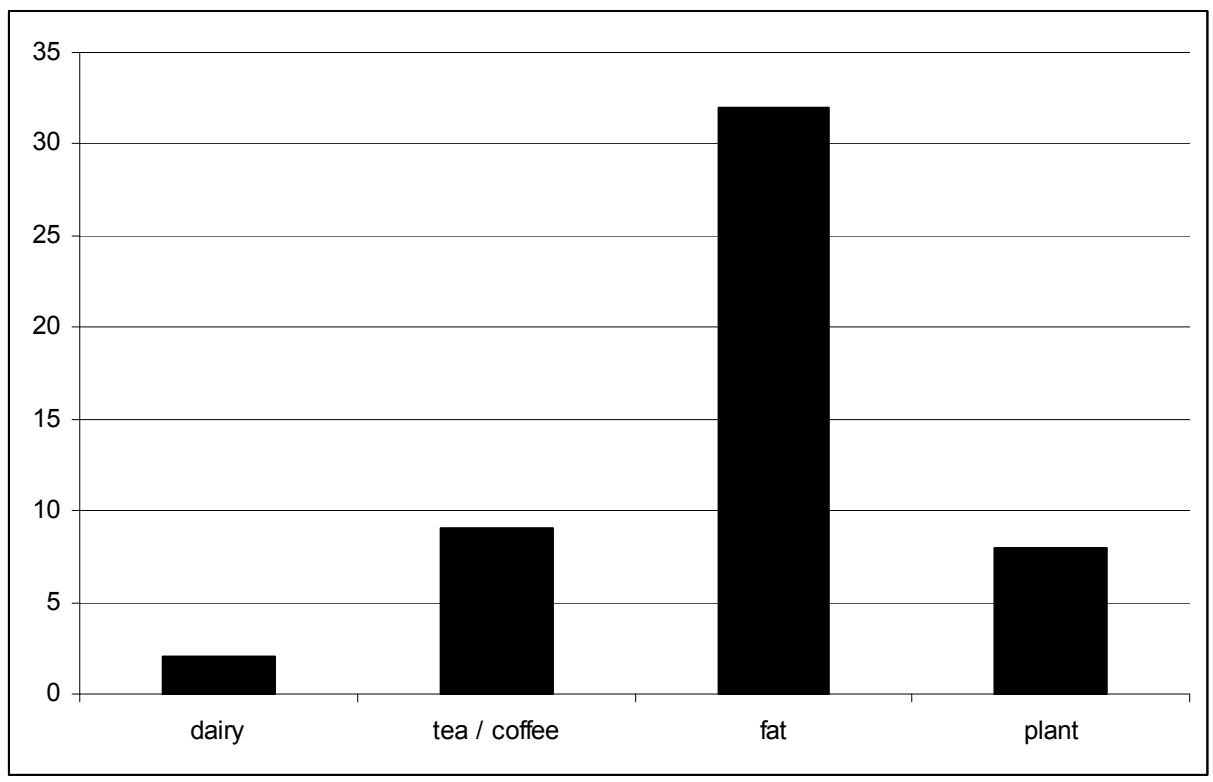

Figure 9: nutrigenomics articles on dairy, tea/coffee, fat and plants $(N=51)$.

Summarising, the growth in numbers of scientific articles on pharmacogenomics and nutrigenomics reveals an increasing interest in these genomics subfields in science. We have seen an increase in patents and publications over time for pharmacogenomics and nutrigenomics. In the next section we will discuss the

Genomics, Society and Policy, Vol.5, No.2 (2009) ISSN: 1746-5354

(C) ESRC Genomics Network. 
implications of these findings for innovation scientists, innovation managers and policymakers.

\section{Conclusions and discussion}

We have demonstrated the usage of patent and publication analysis for identifying hot spots in emerging genomics technologies. This method is especially useful for policymakers when developing and choosing between policy strategies because scientometrics provides insight into new technological developments. However, we argue that scientometrics can only partially influence policy strategy and that more interactive policymaking methods should be employed. This will become clear when we discuss the two parts of our leading research question below.

\section{1) What are the main research fields of emerging pharmacogenomics and nutrigenomics technologies?}

We observed a general upward trend in numbers of scientific articles and patent applications, which shows a growing interest in the genomics subfields of pharmacogenomics and nutrigenomics. There is a good start for patent applications in absolute numbers and we see a significant positive growth compared to all patents. Pharmacogenomics and nutrigenomics are lighting up as hot spots, which are even brighter than the total field of genomics as can be concluded from Figure 2.

Comparison of genomics patents using the NRTA indicator shows that nutrigenomics is especially strong in the Netherlands and Austria, whereas pharmacogenomics is mainly dominant in Italy and France. For nutrigenomics in the Netherlands the findings are not too surprising since the food- and agro-businesses have historically been major drivers for the Dutch economy. ${ }^{42}$ Contrary to a study which found that especially "US groups are larger and better funded", 43 we found more activities in the nutri- and pharmacogenomics subfields in smaller countries. The RTA shows the relative advantage of a technological subfield compared to the overarching field (eg, nutrigenomics compared to genomics) for a specific country. It seems that smaller countries with generally lower GDPs have higher RTAs than larger countries with generally larger GDPs. This might be due to the rather limited amount of resources available for smaller countries, which forces them to make more specialised decisions (ie, focusing on one subfield) because they cannot afford a broad-spectrum policy.

\begin{tabular}{|l|l|l|l|l|}
\hline & Pharmacogenomics patents & $\begin{array}{l}\text { Pharmacogenomics } \\
\text { publications }\end{array}$ & Nutrigenomics patents & $\begin{array}{l}\text { Nutrigenomics } \\
\text { publications }\end{array}$ \\
\hline 1 & $\begin{array}{l}\text { Drugs for disorders in the } \\
\text { digestive system }\end{array}$ & $\begin{array}{l}\text { Drugs for the disorders in the } \\
\text { metabolism }\end{array}$ & Fats & Fats \\
\hline 2 & $\begin{array}{l}\text { Antineoplastics (drugs for } \\
\text { cancer) }\end{array}$ & $\begin{array}{l}\text { Drugs for disorders in the } \\
\text { nervous system }\end{array}$ & Dairy products & Tea and coffee products \\
\hline 3 & $\begin{array}{l}\text { Drugs for disorders in the } \\
\text { urinary system }\end{array}$ & $\begin{array}{l}\text { Drugs for disorders in the } \\
\text { urinary system }\end{array}$ & Tea and coffee products & Plant products \\
\hline 4 & $\begin{array}{l}\text { Drugs for disorders in the } \\
\text { endocrine system }\end{array}$ & $\begin{array}{l}\text { Antineoplastics (drugs for } \\
\text { cancer) }\end{array}$ & Plant products & Dairy products \\
\hline
\end{tabular}

Table I: most important pharmacogenomics and nutrigenomics subfields based on (relative growth of) patents and (absolute number of) publications.

The most important subfields within the pharmacogenomics and nutrigenomics subfields are summarised in Table I for both publications and patents searches.

Genomics, Society and Policy, Vol.5, No.2 (2009) ISSN: 1746-5354

(C) ESRC Genomics Network. 
When the results of the patent and publication searches are compared, it appears that some subfields are hot spots both in the patent and in the publication ranking. This is the case for anticancer drugs and medicines for disorders of the urinary system in the pharmacogenomics field. For nutrigenomics, the fat products seem to be a hot spot in both patents and publication, and dairy products are also very visible. Table I also shows a difference in the order between patents and publications (a disparity that has also been noticed in other studies ${ }^{44}$ ). For example, in nutrigenomics, the order between patents and publication is slightly different, with "fats" occupying the number one position on both lists. This difference in the order of subfields in patents and publications is due to the different focus of organisations: companies apply for a patent on the basis of developments they identify as profitable (eg, dairy is seen as a "health platform" for new functional foods), whereas scientists are interested in exploring unknowns. At the same time, companies might first go for the "low hanging fruit" in an emerging field, only turning to the more demanding developments in a later stage. For nutrigenomics, four subfields were distinguished, whereas for pharmacogenomics, there were more subfields and therefore the difference in patent and publication ranking is more noticeable in the latter.

The hot spot analysis conducted in functional genomics fields needs some critical reflection as well. First, there are some theoretical issues. The use of patent and publication data has some pros and cons, as mentioned above. More fundamentally, one could ask whether it is possible to scan current technology fields for future promises, using these types of data. Hot spots would inherently require some critical mass, while some promising developments may be hiding behind just one patent or publication or within an until-then unconnected field. Starting from the thought that an emerging technology is something new, this might not yet be visible in publications and patents. Scientists might be working within an emerging field but are not yet publishing on it, because they have no findings yet and only engage in agendasetting, or they are even still trying to define what it is they are studying. This might also hold for company R\&D efforts that might not yet have led to patent applications.

Second, while choosing for patent and publication searches, two empirical questions arise: What is the quality of the data? And what is the search demarcation? To answer the first question, the data used came from high quality and widely used databases (eg, Questel). Only for the most recent years may problems arise, due to the update frequency of the patent databases and the latency time between patent application and publication. The search demarcation is rather more difficult. The best way to test this is to take a sample from the resultant search and study its contents for relevance. This has been done for the publication searches and it showed some problems using keywords that define the field. Another route could be to compare the results with findings and expectations coming from other sources. For example, a lot of review articles on pharmacogenomics expect a golden future for cancer genomics, ${ }^{45}$ and in nutrigenomics dairy is in the centre of attention, which is exemplified by the construction of the international Milk Genomics Consortium, ${ }^{46}$ and national initiatives like the Danish Milk Protein Research Consortium, and the New Zealand Milk Health Platform. This triangulation of sources supports the arguments and results. In this 
light, it might be worthwhile to fine-tune the resulting searches by scrutinising their contents and iteratively adjust the keywords used.

\section{2) How do these impact policy strategies?}

Now that we have identified pharmacogenomics and nutrigenomics as emerging technology hot spots, we are presented with an interesting problem, comparable to the Collingridge dilemma: patents and publications can indicate which technological areas, subfields and countries show an above-average growth, and might be winners in which governments should invest (they can "pick" or "back" these winners) and which should be scrutinised by public technology assessment offices for ethical, legal and social impacts. At the same time, patents and publications - but also other measures such as expectation statements - are actually relatively late indicators of an emerging technology. The first signs of such a technology are basic research at universities and in-house R\&D activities in businesses. These activities are not visible to the outside world and cannot be accumulated in order to identify a general trend. Moreover, the exercise could turn out to become a circular argument because past public R\&D might have resulted in patents and publications, which would then end up being a hot spot in which the government should invest (once more).

This dilemma runs parallel with the trade-off governments might face while developing their technology and innovation policy. Over the past few decades governments have changed their view on this kind of policy: 1) from more supplyoriented to demand-oriented knowledge production ${ }^{47}$; and 2) from a more bottom-up process to a more strategic scheme of which $R \& D$ directions to choose. ${ }^{48}$ Countries cannot stimulate every possible technology field and should make choices. This leads to a far more active approach in selecting interesting technology fields. But the question is then: what kind of themes should be selected to be backed by a policy strategy? Themes on which a country's current research and/or valorisation is successful ("nurturing the winners") or themes that are expected to become winners in the future ("backing the winners")?

Another related issue is the legitimisation of government intervention in the genomics fields. R\&D is a major source of newness and technological and socio-economic progress. From a national (innovation system) perspective, governments have several rationales for the stimulation of these $R \& D$ activities ${ }^{50}$ : positive externalities (ie, "benefits from R\&D activities are not fully captured by the R\&D performer" or investor, but also external parties); risk and uncertainty (ie, risk and uncertainty surrounding the investments might deter private investors); network externalities (ie, the benefits only increase when the pool of adaptors increases, which might hinder first movers); asymmetric information (ie, when a party has a knowledge disadvantage over other parties, which makes him reluctant to invest); indivisibilities (ie, large investments are needed to achieve results and "subdivided" efforts will yield no result); and/or evolutionary approaches (ie, advancement through competition and diversity). Governments should take these rationales carefully into account when deciding which emerging technology to support. So the question becomes whether public funding for R\&D should be invested in emerging technologies such as pharmacogenomics and nutrigenomics. Since both nutrigenomics and

Genomics, Society and Policy, Vol.5, No.2 (2009) ISSN: 1746-5354

(C) ESRC Genomics Network. 
pharmacogenomics have to deal with risk and uncertainty about the future and indivisibilities, they might be eligible for R\&D funding.

We would claim that the two questions that governments should ask themselves when setting up their public innovation policy (ie, whether to make policy for an emerging technology, and for which emerging technology) could be only partially answered when using scientometric data, or other more qualitative data for that matter. This again relates to the notion of "newness" as addressed in the introduction: quantitative or qualitative analyses provide insight into new technological developments, but one should be aware of the question whether technologies that were analysed and presented are really new. As we mentioned earlier, stakeholders can differ in their claim of the novelty of a technology, and this range of rhetorical opinions can again be different from the intrinsic novelty of the technology (ie, its properties, the combination of components, the organisational embedding, etc). It might prove to be difficult to discern real from rhetoric novelty, and the question is which methodology should be used. Patents and publications are codified testaments of newness, but also in these documents there is room for rhetoric, especially in the statements about their objectives. It may be fruitful to investigate the assumptions of the stakeholders that underlie their novelty claims.

Apart from this novelty issue, the scientometric data provide policymakers with "objective" measures for what comprises a technology hot spot in their country. They should then assess whether it is legitimate to invest public money in these technologies. They should be aware that this objective information is strongly dependent on past performance of a country, and the performative character of expectations and interpretative flexibility surrounding these technologies undermines this objectivity. On the other hand, policymakers should not be too afraid to also invest, at least a small portion of the public R\&D budget, in "surprise projects" or generic measures that stimulate technological developments that accidentally come to the surface. Innovation and scientometric researchers should work on a more interactive toolbox that provides supportive information to make it easier for policymakers to do just that. Examples of research which focus on this include technology assessment and participatory approaches ${ }^{51}$ user involvement research in innovation studies ${ }^{52}$ and demand-oriented policy measures. ${ }^{53}$

Summing up, the sketched methodological approach comprises articulation of specific hot spots in emerging genomics fields, advising stakeholders around science and technology policy decisions, as well as the management of expectations, visions, and promises. Policymakers can use this method as a starting point for the development and selection of policy strategies. At the same time, this quantitative method only visualises new developments that are already gaining momentum, as articulated in patents and publications. It does not necessarily show really new developments. This can be circumvented by earlier interactions of policymakers with stakeholders in the newly developing fields.

\section{Acknowledgements}

The authors would like to thank Stephan Gauch, Ellen Moors, Simona Negro, and two anonymous reviewers for their comments. We would like to thank our colleagues of

Genomics, Society and Policy, Vol.5, No.2 (2009) ISSN: 1746-5354

(C) ESRC Genomics Network. 
Fraunhofer ISI for their hospitality and professional advice, especially Ulrich Schmoch, Rainer Frietsch, Stefan Kuhlmann and Monica Silbereis.

${ }^{1}$ Rens Vandeberg works at the Dutch Technology Foundation STW and Wouter Boon works at the Athena Institute for Research on Innovation and Communication in Health and Life Sciences of the Vrije University Amsterdam. Correspondence to rensvandeberg@stw.nl

${ }^{2}$ R.O. Van Merkerk and H. van Lente. Tracing emerging irreversibilities in emerging technologies:

The case of nanotubes. Technological Forecasting and Social Change 2005; 72(9): 1094-1111.

${ }^{3}$ J.M. Utterback. 1994. Mastering the Dynamics of Innovation. Boston: Harvard Business School Press.

${ }^{4}$ J.C. Venter et al. The Sequence of the Human Genome. Science 2001; 291(5507): 1304-1351.

${ }^{5}$ The Celera Genomics Sequencing Team. The sequence of the human genome. Science 2001; 291(5507): 1304-1351; The International Human Genome Mapping Consortium. A physical map of the human genome. Nature 2001; 409: 934-941; For a comprehensive overview of the Human Genome Project history, consult http:/www.ornl.gov/sci/techresources/Human_Genome/project/about.shtml

${ }^{6} \mathrm{~J}$. Kaput et al. Nutrigenomics: concepts and applications to pharmacogenomics and clinical medicine. Pharmacogenomics 2007; 8(4): 369-390.

${ }^{7}$ G.S. Omenn. Presidential Address: Grand Challenges and Great Opportunities in Science, Technology, and Public Policy. Science 2006; 314(5806): 1696-1704.

${ }^{8}$ R.H. Eckel, S.M. Grundy \& P.Z. Zimmet. The metabolic syndrome. The Lancet 2005; 365(9468): 1415-1428.

${ }^{9}$ http://www.euro.who.int/obesity

${ }^{10}$ M. Kussmann, F. Raymond \& M. Affolter. OMICS-driven biomarker discovery in nutrition and health. Journal of Biotechnology 2006; 124(4): 758-787.

${ }^{11} \mathrm{~J}$. Kaput et al. Horizons in Nutritional Science - The case for strategic international alliances to harness nutritional genomics for public and personal health. British Journal of Nutrition 2005; 94: 623632.

${ }^{12}$ R.L.J. Vandeberg and E.H.M. Moors. A Framework for Interactive Learning in Emerging Technologies. Journal of Technological Forecasting and Social Change (under review).

${ }^{13}$ EMEA. 2003. Position Paper on Terminology in Pharmacogenetics. European Agency for the Evaluation of Medicinal Products: London.

${ }^{14}$ Royal Society. 2005. Personalised Medicine: Hopes and Realities. The Royal Society: London.

${ }^{15}$ A.D. Roses. Pharmacogenetics and the practice of medicine. Nature 2000; 405: 857-865.

${ }^{16}$ M. Borup et al. The sociology of expectations in science and technology. Technology Analysis \& Strategic Management 2006; 18(3/4): 285-298; N. Brown and M. Michael. A Sociology of Expectations: Retrospecting Prospects and Prospecting Retrospects. Technology analysis \& strategic management 2003; 15(1): 3-18; H. Van Lente. 1993. Promising technology: the dynamics of expectations in technological developments. In Faculteit der wijsbegeerte en maatschappijwetenschappen. Universiteit Twente: Enschede.

${ }^{17}$ N. Brown and A. Webster. 2004. New Medical Technologies and Society. Cambridge: Polity press.

${ }^{18}$ Borup et al, op. cit. note 15 .

${ }^{19}$ Brown \& Michael, op. cit. note 16.

${ }^{20}$ J. Tidd, J. Bessant \& K. Pavitt. 2001. Managing Innovation: Integrating Technological, Market and Organizational Change. Chichester: John Wiley \& Sons (2nd Edition); J. Tidd, J. Bessant \& K. Pavitt. 2005. Managing innovation: integrating technological, market, and organizational change. Chichester, England: John Wiley \& Sons (3rd Edition).

${ }^{21}$ Office of Science and Technology. 2000. Excellence and Opportunity: a Science Policy for the 21st Century. London; J. Schumpeter. 1934. The theory of economic development. London: Oxford University Press.

${ }^{22}$ D. Collingridge. 1980. The Social Control of Technology. London: Pinter.

${ }^{23}$ Technology futures analysis methods working group. Technology futures analysis: toward integration of the field \& new methods. Technological Forecasting and Social Change 2004; 71(3): 287-303; V. Coates et al. On the future of technological forecasting. Technological Forecasting and Social Change 2001; 67: 1-17. 
${ }^{24}$ H. Rothman. 1997. Identifying 'Hot Spots' in Engineerd Biocatalysts - Research and Applications by means of Bibliometics. EC - JRC.

${ }^{25}$ This analysis is based on research we performed in 2004 in order to identify interesting case studies for our research on user involvement in innovation processes concerning genomics.

${ }^{26}$ P. Oldham and A.M. Cutter. Mapping Global Status and Trends in Patent Activity for Biological and Genetic Material. Genomics, Society and Policy 2006; 2(2): 62-91.

${ }^{27}$ Rothman, op. cit. note 24.

${ }^{28}$ A. Kleinknecht, K. Van Montfort \& E. Brouwer. The non-trivial choice between innovation indicators. Economics of Innovation and New Technology 2002; 11(2): 109-121.

${ }^{29}$ A. Jungmittag, G. Reger \& T. Reiss. 2000. Changing innovation in the pharmaceutical industry. Berlin: Springer.

${ }^{30}$ S.J.H. Graham and M.J. Higgins. The Impact of Patenting on New Product Introductions in the Pharmaceutical Industry. MPRA Paper No. 4574 2007; available at SSRN:

http://ssrn.com/abstract $=984628$

${ }^{31}$ G. Vertova. National technological specialisation and the highest technological opportunities historically. Technovation 2001; 21(9): 605-612; C. Hightower and G. Soete. The consortium as learning organization: Twelve steps to success in collaborative collections projects. The Journal of Academic Librarianship 1995; 21(2): 87-91; J. Cantwell and G.D. Santangelo. The new geography of corporate research in Information and Communication Technology (ICT). Journal of Evolutionary Economics 2002. 12: 163-197; P. Patel and K. Pavitt. Is western Europe losing the technological race? Research Policy 1987; 16(2-4): 59-85; I.P. Mahmood and J. Singh. Technological dynamism in Asia. Research Policy 2003; 32(6): 1031-1054.

${ }^{32}$ S. Hinze and U. Schmoch. 2004. Opening the black box. In Handbook of Quantitative Science and Technology Research. H.F. Moed, W. Glaenzel \& U. Schmoch, eds. Kluwer Academic Publishers: Dordrecht: 215-236.

${ }^{33}$ Identification based on the more dynamic European Classification System (ECLA), or the even more dynamic In Computer Only (ICO) classification was dismissed, due to low coverage in available databases.

${ }^{34}$ Hinze \& Schmoch, op. cit. note 32.

${ }^{35}$ See also Box 1.

${ }^{36}$ T. Reiss, S. Hinze \& I.D. Lacasa. Performance of European member states in biotechnology. Science and Public Policy 2004; 31(5): 344-358; OECD. 2004. Biotechnology statistics framework. OECD; U. Schmoch. Double-boom cycles and the comeback of science-push and market-pull. Research Policy 2007; 36(7): 1000-1015.

${ }^{37} \mathrm{http}: / /$ ep.espacenet.com/search97cgi/s97_cgi.exe?Action=FormGen\&Template=ep/EN/home.hts

${ }^{38}$ A.M. Hedgecoe. Terminology and the Construction of Scientific Disciplines: The Case of Pharmacogenomics. Science, Technology, \& Human Values 2003; 28/(4): 513-537; W.P.C. Boon and R.O.v. Merkerk. Prospective Positioning of Industrial Players: the case of theranostics. Technology analysis \& strategic management 2009; 21(4): 471 - 489.

${ }^{39}$ All publications are abstracted from these databases in October 2005.

${ }^{40}$ Moreover, the trends were calculated based on country-specific data, which also showed an upward trend over all countries. Regarding the growth of pharmacogenomics patents for different countries and years, Austria, Denmark, Spain, the Netherlands, and Germany are the top countries, while the US, Great Britain and France score relatively weakly.

${ }^{41}$ Although the term pharmacogenetics has been used since 1959. Hedgecoe discussed the use of the terms pharmacogenetics and pharmacogenomics in . A.M. Hedgecoe. Terminology and the Construction of Scientific Disciplines: The Case of Pharmacogenomics. Science, Technology, \& Human Values 2003; 28/(4): 513-537.

${ }^{42}$ Ministerie van Economische Zaken. 2004. Actieplan Life Sciences: kansen grijpen, knelpunten aanpakken. Ministerie van Economische Zaken: Den Haag.

${ }^{43}$ M.M. Hopkins et al. Putting pharmacogenetics into practice. Nature Biotechnology 2006; 24(4): 403410.

${ }^{44}$ Ibid

${ }^{45}$ Royal Society, op. cit. note 14; PriceWaterhouseCoopers. 2005. Personalized medicine: the emerging pharmacogenomics revolution. PriceWaterhouseCoopers - Global technology centre - Health research institute. 


\footnotetext{
${ }^{46}$ J.B. German et al. International milk genomics consortium. Trends in Food Science \& Technology 2006; 17(12): 656-661.

${ }^{47}$ R. Smits and S. Kuhlmann The Rise of Systemic Instruments in Innovation Policy. International Journal of Foresight and Innovation Policy 2004; 1(1/2): 4-32.

${ }^{48}$ D. Van de Ka. Picking the winners by consensus: Grant-giving practice in the Netherlands. Higher Education 1994; 28: 59-83.

${ }^{49}$ B.R. Martin. 1997. Technology Foresight as a Tool for Strategic Management. In Managing Technology for Competitive Advantage, J. Anderson, R. Fears \& B. Taylor, eds. Cartermill International: London: 31-47.

${ }^{50}$ W. Polt and J. Rojo. 2004. Policy Instruments. In Handbook on the evaluation of Research and Technology Policy, W. Polt and J. Rojo, eds. Elgar Publishers: 29-68.

${ }^{51}$ R.O. Van Merkerk and H. van Lente. Tracing emerging irreversibilities in emerging technologies: The case of nanotubes. Technological Forecasting and Social Change 2005; 72(9): 1094-1111.

${ }^{52}$ Moors, E.H.M., Enzing, C., Giessen, A. van der \& Smits, R.E.H.M (2003). User-Producer Interactions in Functional Genomics Innovations. Innovation: Management, Policy \& Practive 5(2-3): 120-143.

${ }^{53}$ J. Edler and L. Georghiou. Public procurement and innovation-Resurrecting the demand side. Research Policy 2007; 36(7): 949-963.
} 


\section{Annex A: IPC classes used}

Nutrition: A01G, A01H, A01J, A23C, A23D, A23F, A23J, A23L, A23P, C07G NOT C07G-011

Pharmacology: A61K038, A61K039, A61K048, A61K049, A61K051, A61P001, A61P003, A61P005, A61P007, A61P009, A61P011, A61P013, A61P015, A61P017, A61P019, A61P021, A61P023, A61P025, A61P027, A61P029, A61P031, A61P033, A61P035, A61P037, A61P039, A61P041, A61P043, C12Q001-68

Genomics: A61K-031, A61K-033, A61K-035, A61K-038, A61K-039, A61K-041, A61K-047, A61K049-00, A61K-048, C12N-015, C07H-021/02, C07H-021/04, C07G, C07K-004, C07K-014, C07K-016, C07K-017, C07K-019, C12F-003/04, C12F-003/08, C12F-003/10, C12F-005, C12N-001, C12N-003, C12N-007, C12N009, C12N-011, C12N-013, C12P NOT C12P-033, C12S, C13K 


\section{Annex B: Publication search strategies}

Table: the two search strategies for defining the two genomics fields. For every strategy the keywords used and the number of publications found are displayed.

\begin{tabular}{|c|c|c|c|}
\hline Genomics field & Strategy 1: & Strategy 2: & Combination \\
\hline Pharmacogenomics & $\begin{array}{l}\text { 'pharmacogenomic(s)', } \\
\text { 'pharmacogenetic(s)' - } 6385\end{array}$ & $\begin{array}{l}\text { Genetics ('gene expression, } \\
\text { RNA, DNA, variation, } \\
\text { mutation, alteration, SNP') } \\
\text { AND } \\
\text { Pharmacology ('drug } \\
\text { development, drug design, } \\
\text { drug discovery, clinical } \\
\text { development, clinical trials, } \\
\text { target validation, drug target, } \\
\text { pre-clinical development, } \\
\text { disease development, disease } \\
\text { pathway, disease mechanism, } \\
\text { pathogenesis, drug } \\
\text { metabolism, drug action, } \\
\text { pharmaceutical') AND } \\
\text { Medicine ('diagnostics, } \\
\text { diagnosis, therapeutics, } \\
\text { treatment, prevention, cure, } \\
\text { drug efficacy, drug safety, } \\
\text { adverse drug reaction, disease } \\
\text { susceptibility, disease } \\
\text { preposition, drug response') - } \\
\text { 17290 }\end{array}$ & $\begin{array}{l}\text { Strategy } 1 \text { OR strategy } 2- \\
22940\end{array}$ \\
\hline Nutrigenomics & $\begin{array}{l}\text { 'nutrigenomic(s)', } \\
\text { 'nutrigenetic(s)'-108 }\end{array}$ & $\begin{array}{l}\text { Genetics ('genetic(s), } \\
\text { genomic(s)') AND } \\
\text { Nutrition ('nutrition, } \\
\text { nutritional, nutricial, } \\
\text { nutraceutical, nutriceutical, } \\
\text { nutrient, food factor, dietary } \\
\text { compound, functional food, } \\
\text { supplement pill, dietary } \\
\text { intervention') AND Disease } \\
\text { ('cancer, obesity, obisitas, } \\
\text { cardio vascular disease, } \\
\text { cardiovascular disease, non } \\
\text { insulin dependent diabetes, } \\
\text { type } 2 \text { diabetes, adult onset } \\
\text { diabetes, osteoporosis, } \\
\text { metabolic syndrome')-1517 }\end{array}$ & $\begin{array}{l}\text { Strategy } 1 \text { OR strategy } 2- \\
1579\end{array}$ \\
\hline
\end{tabular}

${ }^{1}$ The displayed list is only a representation; a full version would be too comprehensive. 